\title{
Factor Affecting the Information Sources and Communication Channels toward Pig Farmer's Perception of African Swine Fever in Tra Vinh Province, Vietnam
}

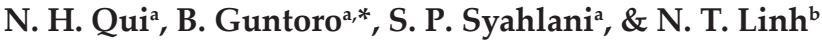 \\ aDepartment of Livestock Social Economics, Faculty of Animal Science, Universitas Gadjah Mada, \\ Jalan Fauna 3, Bulaksumur, Yogyakarta, Indonesia 55281 \\ bDepartment of Veterinary and Animal Husbandry, School of Agriculture and Aquaculture, Tra Vinh University, \\ No. 126 Nguyen Thien Thanh Street, Ward 5, Tra Vinh City, Tra Vinh Province, Vietnam \\ *Corresponding author: budiguntoro@ugm.ac.id \\ (Received 18-06-2020; Revised 27-07-2020; Accepted 13-08-2020)
}

\begin{abstract}
The study was conducted to estimate factors affecting the information sources and communication channels that were used by pig farmers to access information about African Swine Fever (ASF) in Tra Vinh Province, Vietnam, and to determine the perception of pig farmers about ASF epidemic. The survey used the questionnaires to gather data from 150 pig farmers which was conducted in a purposive method and was analyzed by multiple logistic regression model. The respondents were pig farmers who had experienced at least one year and have been affected by ASF epidemic in raising or trading pigs and other activities of the value chain. The result showed that the decision to choose information from government extension worker as the main information resource was affected by gender, pig herd size, informal education, and formal education $(\mathrm{p}<0.01)$ while only gender and education affecting the choice of farming visit as their communication channel $(p<0.01)$. When farmers can access to ASF information, they know how to anticipate the disease and deal with the outbreak. It was concluded that socio- demographic have affected the choice of information sources while only gender and formal education affected communication channels. Furthermore, when accessing information sources and communication channels, pig farmers had an awareness of basic information about ASF.
\end{abstract}

Keywords: ASF; communication channel; information source; perception; pig farmer

\section{INTRODUCTION}

The pig sector is one of the important sectors in Vietnam which has mostly been distributed to Vietnamese nutrition. In the context of African Swine Fever (ASF) in Vietnam, a lot of farmers have gone out of business. The first months of 2019, ASF has emerged in Vietnam and had a strong effect on the pig production system. ASF has culled 6 million swine (FAO, 2020).

Information sources and communication channels are necessary for farmers to control diseases and improve farmer's productivity. Livestock farming could be accessed by different sources (Brhane et al., 2017) and disseminated using various channels (Angello, 2015). In the diffusion of information, information providers had to make sure their information was disseminated to the farmers and satisfied the need of farmers (Msoffe \& Ngulube, 2016). Moreover, one source of information cannot satisfy farmers and this is the reason why farmers usually choose multiple sources of information (Mittal et al., 2015).

Amongst farmers in developing countries, the common traditional channel is face-to-face communication which was used for a long time ago (Msoffe \& Ngulube,
2016). In the same way, Akinbile \& Otitolaye (2008) recorded that farming visit and radio were the common communication channels used by the respondents in the research. Discussion with farm veterinarians was confirmed by a large number of farmers (79\%) and other favored sources of information such as the internet (web pages of animal heath associations), government extension, and academic information were also recorded (Frossling \& Noremark, 2016). Information from government extension and the other farmers was relevant and quickly accessed (Kipkurgat, 2015; Frossling \& Noremark, 2016; Mapiye et al., 2019). When the animal disease outbreak, messages sent by handphone, radio, e-mail, local information meeting were considered as the effective communication channels by many farmers (Frossling \& Noremark, 2016; Aldosari et al., 2019). In case of cattle enterprises, a public extension was the main source of information, followed by other farmers (Motiang \& Webb, 2015). Sebeho \& Stevens (2019) also debated that farmers realized the extension advisors as the main source of information.

In previous studies, there were various researches about the sources of information and communication channels, but their results mostly mentioned the condi- 
tion of normal status and only limited studies focused on the ASF epidemic. There were several effects of socio-demographic profiles on the choices of information sources and communication channels. Melesse et al. (2018) debated that the utilization of published meetings, village meetings, and neighbors to access and diffuse information was determined by age and educational status. Social-demographic profiles such as gender, age, farming experience, education of household head, farm size, land ownership, and group membership have significantly influenced the access to information sources in agriculture fields (Mbanda-Obura et al., 2017). The choice of government extension as the main source of information was affected by gender and informal education (Mtega et al., 2016; Mbanda-Obura et al., 2017; Mapiye et al., 2019). Guntoro et al. (2016) showed that friends or other farmers became an important source of information for farmers. In addition, informal education, formal education, Internet, and extension had significant roles as sources of information (Guntoro et al., 2016). The choice of communication channels are affected by age, education, and farm size (MbandaObura et al., 2017). Aldosari et al. (2019) showed that age and education of respondents had strongly affected the application of information through electric media such as TV and radio but farming experience had no effect on this media channels. Besides that, electronic media including TV programs, can enhance knowledge significantly (Nazari \& Hassan, 2011). Additionally, mass media gave effective channels for communication in agricultural fields which could increase the knowledge and affect the behavior of farmers (Nazari \& Hassan, 2011). The education of farmers significantly affected the application of information from radio, but there was no correlation effect between farming experience and the application of information from radio and TV (Aldosari et al., 2019). As the same results, Motiang \& Webb (2015) debated that gender and education affected the choice of communication channels.

Tra Vinh is one of the provinces in Mekong Delta where farmers have largely referred to agricultural activities. In addition, Vietnamese consume pork every day and it has become a part of Vietnamese culinary. Since the confirmation of ASF in Vietnam from the first months of 2019, information sources and communication channels have been very important for pig farmers to access information about ASF. Additionally, farmers in Tra Vinh Province usually get information about disease and farming activities from government officers. This condition indicated that there were less sources of information available for farmers and they have difficulties in choosing the available channels of information to be used. Furthermore, there were not many studies focusing on pig farmers in Tra Vinh Province. That was the reason why the study was conducted. It was expected that the better performance of social demographic profiles led to the choice of the government-extension worker as a main source of information. In similar to information resource, farming visit was also expected as main communication channels of pig farmers. The hypothesis was supported by Mtega et al., (2016), Mbanda-
Obura et al., (2017), Melesse et al. (2018), and Mapiye et al., (2019).

This study aimed to determine and estimate factors affecting the choice of information sources and communication channels that farmers used in the value chain of pig to access information about ASF that will determine the perception of pig farmers about ASF.

\section{METHODS}

\section{Location}

Tra Vinh is one of 13 provinces in Mekong Delta in Vietnam where the majority of farmers have focused on agricultural activities and are known as the poorest province in Mekong Delta. The study was conducted in three districts of Tra Vinh Province, namely Tieu Can District, Cang Long District, and Cau Ke District with pig populations of 44,999, 43,467, and 31,157 pig heads, respectively (GSO, 2019) where pig production was seriously affected by ASF and pig population was much more than others (Figure 1).

\section{Data Collection}

The survey was started from May 1, 2020 to June 10, 2020 to get data from the pig farmers as the period of ASF epidemic are still available in Vietnam. The sections of the questionnaire included socio-demographic profiles, information sources, communication channels, and perception of pig farmers toward the ASF epidemic. The survey was in the local language (Vietnamese), as below:

The first, the survey was found out the social-demographic profiles such as gender, age, family member, formal education, and informal education.

The second, pig farmers were asked to find out the information sources and communication channels relating to ASF. There were two sections to get this information. Firstly, farmers were asked to find out all of information sources and communication channels. Secondly, farmers were asked which one is the most favorite information source and the most favorite communication channel.

The third, perception of farmers about ASF was evaluated by the questions using Likert scale. Likert scale was used to assess the performance after an educational intervention (Gail \& Anthony, 2013). In this study, Likert scale was used to estimate the perception of pig farmers about ASF when using information sources and communication channels.

A total of 150 respondents were surveyed following the questionnaires to collect the primary data. Because of the unknown population of pig farmers who have been affected by ASF, the number of respondents was chosen by following the formulation of Tabachnick \& Fidell (1996) as below:

$$
\mathrm{N}=50+8^{*} \mathrm{n}
$$

where $\mathrm{N}$ refers to the number of respondents of the study and $\mathrm{n}$ refers to independent variables of the study.

There were 7 independent variables (gender, age, family size, formal education, informal education, farm 
size, and income status). From the formulation, we should choose 106 pig farmers who have been affected by ASF as minimal respondents. However, by quota sampling, we chose 150 responders to make sure the number of respondents was precise and to balance the number of respondents between research areas (50 respondents per district). A total of 150 respondents were face-to-face interviewed following the questionnaires. The sections of the questionnaire included socio-demographic profiles, information sources, communication channels, and the perception of pig farmers about ASF epidemic.

A purposive sampling method was used to randomly chose a sample size of 150 pig farmers following information from the list of farmers provided by the government staff and animal feed seller. Pig farmers, who have experience at least one year in raising pigs and have been affected by ASF epidemic in trading or raising pigs, were chosen as respondents. Because when farmers have experience, they can know clearly how to access information about pig disease and how to deal with the problem on their pig farm.

\section{Data Analysis}

Data were analyzed by STATA 14.0 and Excel 2013. Likert scale was used to estimate the perception of pig farmers about ASF when using information sources and communication channels with strongly agree, agree, undecided, disagree, and strongly disagree. A descriptive analysis was used for these data. There were two parameters used to estimate farmer's perception of ASF epidemic. The first parameter was ASF prevention information. The second parameter was ASF assistant information. Besides, in a previous study, Guinat et al. (2016) used two parameters to determine pig farmer's knowledge and behavior towards ASF, which were clinical suspicion and reporting with a total of 12 questions. Additionally, the questionnaires were checked by Pearson correlation.

Multiple Logistic Regression (MLR) was used in this study to analyze the influence of socio-demographic profiles on the choice of information sources and communication channels of pig farmers in the context of ASF epidemic. Values of $p<0.05$ and $p<0.01$ were considered as a statistical significance.

MLR showed the relationship between nominal dependent variables (usually more than two variables) and multiple independent variables (Lind et al., 2018). The logistic model used the baseline-category logits with a predictor $\mathrm{X}$ as follow:

$$
\ln (p / 1-p)=\beta_{0}+\beta_{i} X_{i^{\prime}}, i=1, . ., I-1
$$

where $p$ refers to the probability of farmer's choice of information sources and communication channels; 1-p was the probability of government-extension worker/ farming visit, ( $\mathrm{p} / 1-\mathrm{p})$ refers to odd ratio of farmer's choice, $\beta_{0}$ refers to constant, $X_{i}$ refers to vector of independent variables and $\beta_{\mathrm{i}}$ refers to parameter estimate for the $i^{\text {th }}$ independent variable

MRL showed the influence between the dependent variable (the choice of farmers) and multiple independent variables (gender, age, family member, formal education, informal education, farm size, and income status) which were presented in Table 1.

The use of MRL was to explore the relationship between social-characteristics and information sources and communication channels. The choice of information

Table 1. Operational definition for the study

\begin{tabular}{|c|c|}
\hline Variables & Definitions \\
\hline \multicolumn{2}{|l|}{ Dependent variables } \\
\hline $\begin{array}{l}\text { The choice of favorite infor- } \\
\text { mation resource }\end{array}$ & $\begin{array}{l}\text { The most favorite ASF information resource that farmers accessed }(4=\text { Government extension } \\
\text { worker, } 3=\text { Farmer-to-farmer, } 2=\text { Private extension worker, } 1=\text { Other information source such as } \\
\text { feed seller) }\end{array}$ \\
\hline $\begin{array}{l}\text { The choice of favorite com- } \\
\text { munication channel }\end{array}$ & $\begin{array}{l}\text { The most favorite channel that farmers used to communicate }(1=\text { Farming visit; } 2=\text { Electronic me- } \\
\text { dia (mobile, TV, radio, and Internet), } 3=\text { Other channel such as printed media) }\end{array}$ \\
\hline \multicolumn{2}{|l|}{ Independent variables } \\
\hline Gender & Gender of pig farmers who were chosen as respondents (1=Male, $0=$ Female). \\
\hline Age & The age of farmers from the date of their born to the last birthday (Continuous) \\
\hline Family member & The number of members in the family (Continuous) \\
\hline Pig herd size & The number of pigs in farmer's farm (Continuous) \\
\hline Formal education & $\begin{array}{l}\text { The education of farmers in the school }(1=\text { primary school, } 2=\text { secondary school, } 3=\text { high school, } \\
4=\text { bachelor) }\end{array}$ \\
\hline Informal education & The frequency that pig farmers joined in training, meeting, conference $(1=y e s, 0=$ not yet) \\
\hline Income status & $\begin{array}{l}\text { Income that pig farmers earned from raising pigs per month } \\
(1="<200 \$ " ; 2=\text { " } 200-400 \$ " ; 3=\text { " }>400 \$ ")\end{array}$ \\
\hline \multicolumn{2}{|l|}{ Descriptive variables } \\
\hline Information sources & Refers to all of information sources that farmers used \\
\hline Communication channels & Refers to all of channels diffusing information to farmers \\
\hline ASF prevention information & Perception of farmers refers to how to deal with ASF epidemic when received information \\
\hline ASF assistant information & $\begin{array}{l}\text { Perception of farmers refers to policies information regarding ASF epidemic when received } \\
\text { information }\end{array}$ \\
\hline
\end{tabular}

Note: ASF= African Swine Fever 
sources and communication channels was expected to be changed by a certain factor if any independent variables increase by one unit.

\section{RESULTS}

\section{The Description of Demographic Characteristics of Pig Farmers}

The socio-demographic profiles of pig farmers, including gender, age, family member, formal education, informal education, farm size, and income status, showed that male farmers accounted for $65.53 \%$. Farmers in this study were in middle ages with average of 35 years old who joined in pig raising activities. In addition, farmers in this study had high experience in raising pigs with average of 7-8 years of experience. Formal education was conducted for all of pig farmers in the study with $35.5 \%$ farmers completed high school and $18.67 \%$ of farmers in the study completed a bachelor's degree. Farmers in this study owned an average of 110 pigs per farm with around 4 members in their family. A total of $60.67 \%$ of farmers in the study confirmed that they have joined in training and conference regarding raising pigs. Additionally, $40 \%$ of respondents said that they earned $200-400 \$$ per month from raising pigs.

\section{Information Sources and Communication Channels Used by Pig Farmers}

There were four information sources available which were information from government-extension worker, private-extension worker, other farmers, and other sources (Table 2). A total of $86.6 \%$ of respondents (130/150 respondents) chose information from government-extension workers as their main information resources. Private extension workers, farmer-to-farmer, and other resources were also recorded in this study, but there was less preference compared to information from the government.

Table 2 also recorded the communication channels which were used by pig farmers in Tra Vinh Province as well. A total of $81.3 \%$ of farmers (122/150 respondents)

Table 2. All of information sources and communication channels used to use by respondents in Tra Vinh Province

\begin{tabular}{lc}
\hline Criteria & Percentage $^{*}(\%)$ \\
\hline Information sources & \\
Government extension worker & 86.6 \\
Private extension worker & 46.6 \\
Farmer-to-farmer & 20.0 \\
Other resource such as feed seller & 10.0 \\
Communication channels & \\
Farming visit & 81.3 \\
Electronic media (mobile, TV, radio, and & 36.6 \\
internet) & \\
Other channels such as printed media & 22.6 \\
\hline
\end{tabular}

Note: ${ }^{*}=$ one farmer could choose more than one answer. Information sources and communication channels have been used by farmers to get or discuss information about African Swine Fever. Source: primary data. confirmed that farming visit was their main communication channels. However, there were not many farmers confirmed that they used electronic media (such as mobile phone, Internet) and other channels.

\section{Factors Affecting the Choice of Pig Farmers}

Table 3 and Table 4 showed that the likelihood ratio chi-square of 188.05 with a $p<0.0000$ told us that our model as a whole fit significantly better than an empty model. Besides that, pseudo $\mathrm{R}^{2}$ was 0.2608 . It was clear that all of the information in this study could precisely explain the choice of information sources which was made by pig farmers. The results illustrated that the choice of information sources of pig farmers depended on their gender, pig herd size, formal education, and informal education. However, there were only gender and formal education that affected the choice of communication channels.

Information from government-extension workers was the baseline outcome of the model $(p<0.01)$. Table 3 also showed that the multinomial logit for gender, male relative to female was 3.599 unit lower for preferring information from other sources compared to governmentextension worker, given all other predictor variables in the model are held constant. In other words, male farmers were more likely than female farmers to prefer information resources from government-extension workers. An increase in pig herd size decreased pig farmers' livelihood to choose information from private extension workers and farmer-to-farmer than government-extension workers. Besides, an increase in formal education increased pig farmers' livelihood to choose information sources from government-extension workers than private-extension workers, farmer-to-farmer, and other sources. Farmers who joined in informal education such as training and conferences preferred choosing information from government-extension workers to other sources. Other socio-demographic profiles did not affect the choice of information sources $(p>0.05)$.

In Table 4 , the likelihood ratio chi-square of 81.22 with a $p<0.0000$ told us that our model as a whole fit significantly better than an empty model with the pseudo

Table 3. Factors affecting the choice of information sources

\begin{tabular}{lccc}
\hline Variables & $\begin{array}{c}\text { Private exten- } \\
\text { sion worker }\end{array}$ & $\begin{array}{c}\text { Farmer-to- } \\
\text { farmer }\end{array}$ & $\begin{array}{c}\text { Other } \\
\text { source }\end{array}$ \\
\hline (Feed seller) & -1.149 & 0.3591 & $-3.599^{* *}$ \\
Gender & -0.0192 & 0.0216 & 0.0183 \\
Age & 0.2242 & 0.2083 & 0.0079 \\
Family member & 0.0819 & 0.0257 & 0.2016 \\
Experience & $-0.0617^{* *}$ & -0.0099 & $-0.1393^{* *}$ \\
Pig herd size & $-1.549^{* *}$ & $-1.021^{* *}$ & $-2.709^{* *}$ \\
Formal education & -1.133 & -0.3765 & $-3.018^{* *}$ \\
Informal education & 1.091 & -0.6298 & -0.8207 \\
Income status & $6.503^{*}$ & 2.972 & $12.90^{* *}$ \\
Constants & &
\end{tabular}

Note: Number of observations $=150 ; \mathrm{Chi}^{2}=188.05 ;$ Prob $>\mathrm{chi}^{2}=0.0000$; Pseudo R2=0.524; ${ }^{*}=\mathrm{p}<0.05 ;{ }^{*}=\mathrm{p}<0.01$; Government extension worker was baseline outcome. Source: primary data. 
Table 4. Factors affecting the choice of information sources

\begin{tabular}{lcc}
\hline Variables & $\begin{array}{c}\text { Electronic } \\
\text { media }\end{array}$ & $\begin{array}{c}\text { Other channel } \\
\text { (Printed document) }\end{array}$ \\
\hline Gender & $-1.478^{* *}$ & -0.7092 \\
Age & -0.0231 & -0.0151 \\
Family member & 0.1974 & -0.0345 \\
Experience & 0.0096 & 0.0111 \\
Pig herd size & -0.0073 & -0.0056 \\
Formal education & $-0.7982^{* *}$ & $-1.005^{* *}$ \\
Informal education & -0.2949 & -0.3783 \\
Income status & -0.7539 & -0.7627 \\
Constants & $4.741^{* *}$ & $5.243^{* *}$ \\
\hline
\end{tabular}

Note: Number of observations $=150 ; \mathrm{chi}^{2}=81.22 ;$ Prob $>\mathrm{chi}^{2}=0.0000$; Pseudo R2=0.2608; ${ }^{* *}=\mathrm{p}<0.01$; Farming visit was baseline outcome. Source: primary data.

$\mathrm{R}^{2}$ was 0.2608 . Table 4 showed that an increase in formal education increased pig farmers' livelihood to choose farming visits as the favorite communication channel than electronic media and other channels. Besides, an increase in age of pig farmers, increased the livelihood of pig farmers to choose farming visit as the favorite communication channel than electronic media.

\section{Farmer's Perception of ASF}

Information sources and communication channels have a relationship with the perception of farmers about ASF. The sources of information and communication channels are the most important tools to disseminate ASF information to them. In the context of ASF epidemic, farmer's perception about ASF is necessary. In this study, pig farmers were asked 10 questions regarding basic information about ASF (Table 5).

Following ASF prevention information parameter, when respondents accessed information sources and used communication channels, there was $52.2 \%-85 \%$ farmers who confirmed "strongly agree", 10.4\%-37.3\% farmers in the study confirmed "agree", $2.6 \%-10 \%$ of farmers confirmed "undecided", 1.3\%-6.6\% of farmers confirmed "disagree", and $0.6 \%$ farmers confirmed "strongly disagree" with these statements. Due to their confirmation, we can know that respondents know how to prevent ASF epidemic and deal with the outbreak.

Additionally, following ASF assistant information, no one confirms "disagree" or "strongly disagree" with these statements. Around $57.4 \%-73.4 \%$ of respondents confirmed "strongly agree" with the statement "ASF is a dangerous disease", "ASF can cause high death rate in pigs" and "Government has the policy to help farmers affected by ASF". About $20 \%-42.6 \%$ of respondents showed that they agreed with these statements. Furthermore, only $0.6 \%$ of respondents showed "undecided" for the statement "We should tell government agents when our pigs have a disease of ASF" and 6.6\% of respondents gave "undecided" for the statement of "We should buy pork which has quarantine-stamp". It could prove that farmers were aware of ASF epidemic and had basic knowledge when accessing information sources and communication channels such as how to prevent and deal with the ASF outbreak. However, there were a few pig farmers replied "disagree" and "strongly disagree".

\section{DISCUSSION}

It was clear that information from governmentextension worker was official information which was disseminated to the farmers through extension worker. Besides, information from the government is accurate, precise, and reliable (Kipkurgat, 2015). These results were in line with the study of Kipkurgat (2015), Frossling \& Noremark (2016), Mapiye et al. (2019), and Sebeho \& Stevens (2019). Most of fees from government-extension workers in Vietnam were free, but for other information sources, farmers had to pay for the high cost (private-extension worker) or were not reliable (farmer-to-farmer and other resources). These conditions were also recorded in the study of Kipkurgat (2015).

Mittal et al. (2015) recorded that farmers chose information from multiple sources to satisfy themselves.

Table 5. The perception of pig farmers when accessing information sources and communication channels (\%)

\begin{tabular}{|c|c|c|c|c|c|}
\hline Statement & SA & A & UD & $\mathrm{D}$ & SD \\
\hline \multicolumn{6}{|l|}{ ASF prevention information } \\
\hline ASF is a dangerous disease & 74 & 26 & - & - & - \\
\hline There is no vaccine or treatment for ASF & 76.1 & 20.6 & 3.3 & - & - \\
\hline On-farm biosecurity is key to prevent ASF outbreak & 80.8 & 14.6 & 3.3 & 1.3 & - \\
\hline ASF can cause high death rate in pigs & 66 & 34 & - & - & - \\
\hline ASF can directly transmit from infected pigs to healthy pigs & 85 & 10.4 & 2.6 & 2 & - \\
\hline $\begin{array}{l}\text { The virus can survive for several months in fresh pork and processed } \\
\text { pork products }\end{array}$ & 54.3 & 37.3 & 5.3 & 3.3 & - \\
\hline Increasing pig herd size is high risk in the context of ASF outbreak & 52.2 & 30.6 & 10 & 6.6 & 0.6 \\
\hline \multicolumn{6}{|l|}{ ASF assistant information } \\
\hline Government has policy to help farmers affected by ASF & 57.4 & 42.6 & - & - & - \\
\hline We should buy pork which has quarantine-stamp & 73.4 & 20 & 6.6 & - & - \\
\hline We should tell government agents when our pigs have disease of ASF & 70.8 & 28.6 & 0.6 & - & - \\
\hline
\end{tabular}

Note: $\mathrm{SA}=$ Strongly agree; $\mathrm{A}=$ Agree; $\mathrm{UD}=$ Undecided; $\mathrm{D}=$ Disagree; $\mathrm{SD}=$ Strongly disagree; ASF= African Swine Fever. Source: primary data. 
Electronic media provided helpful information to farmers, especially in ASF epidemic. Pig farmers used electronic media to prevent contact with others which could be an infected resource of ASF. These conditions were also recorded in several studies (Lindström et al., 2012; Frossling \& Noremark, 2016; Aldosari et al., 2019). However, in the present study, farmers preferred farming visits because they could get information directly, relevant, and fast. Besides, information from Internet is diverse which is difficult to recognize whether this information is reliable or not. These results were similar to the study of Akinbile \& Otitolaye (2008), Lindström et al. (2012), Frossling \& Noremark (2016), and Aldosari et al. (2019). The studies of Akinbile \& Otitolaye (2008), Frossling \& Noremark (2016), Aldosari et al. (2019), and Mbanda-Obura et al. (2017) also debated that local meeting or farming visit was helpful for farmers.

The results proved that male was dominant in the choice of information resource and they preferred to get information from extension worker. The result was similar to the result of Mtega et al. (2016), Mbanda-Obura et al. (2017), and Mapiye et al. (2019). It can be explained by the fact that male had stronger decision making in household. Besides, man had more free time than woman after activities on the farm because they may not join in household activities, so man can meet and share information with government-extension worker who provides the official information. Additionally, woman has to do their housework, prepares for meals, and takes care of their children. This condition was also recorded in the study of Mtega et al. (2016). The results showed that when farmers owned more pig, they tended to discuss with government-extension workers because they knew their farms faced with the high risks of ASF. Therefore, they gave more concern on information sources. Furthermore, more educated farmers chose information from government-extension workers. Because farmers had high formal education and informal education realized that information from the government was official, reliable, and can satisfy their needs. Therefore, farmers could discuss ASF with government-extension worker who had expertise in this field. It was clear that farmers with accessing training or conferences were better at understanding information from government-extension workers. The study of Mtega et al. (2016), Mbanda-Obura et al. (2017), Mapiye et al. (2019), and Melesse et al. (2018) showed a similar result to this study.

The results also showed that gender and formal education affected the choice of communication channels. These results were recorded in the result of Motiang \& Webb (2015). Other factors of socio-demographic profiles did not affect the choice of communication channels. The communication channels were only affected by gender and formal education. Male preferred communication channels through farming visit compared to electronic media. As the same result with information sources, gender also affected communication channels. The man had a stronger decision in choosing communication channels because they had more time than woman. This condition was also recorded in the study of Aldosari et al. (2019). Formal education of pig farmers was higher, and farmers had a stronger decision making in choosing electronic media as the main communication channel. When visited the other farms, the farmer could gain more knowledge as well as exchange ASF news, technology, and biosecurity in farm. Additionally, relevant farmers had relevant information that was useful in disseminating information (Kipkurgat, 2015). Guntoro et al. (2016) and Mbanda-Obura et al. (2017) also showed the same results. We can see that when we used the information source and communication channel to diffuse information, we should consider gender, formal and informal education, as well as the size of pig herd owned by the farmers.

However, there was no effect of age, experience, family member, and income status on information sources and communication channels in the current study. It was similar to the statement of Aldosari et al. (2019) that the experience had no effect on the choice of communication. The current result was not similar to the previous study of Mbanda-Obura et al. (2017) and Melesse et al. (2018), who debated the choice of information resource depended on social-demographic profiles such as age. It can be explained by the fact that young or old farmers had the same right to access information resources and experience, family members, and income status were more helpful in managing farming systems than accessing information sources.

Following pig farmers' answers about the ASF epidemic's basic information, it was clear that almost all farmers had basic knowledge when accessing ASF information through information sources and communication channels. First, they knew the dangerousness of disease, and then they know improving biosecurity on-farm is a good way to control a disease outbreak. Information sources and communication channels also affected their decision making in managing pig herd size. Besides, decision making of farmers was strongly affected by the number of information sources that were able to be accessed by the farmers (Msoffe \& Ngulube, 2016). Farmers who had more information would make a wise decision, thus, increased their farm activities (Kante et al., 2017). This result was similar to the statement of Kante et al. (2017) that farmers having more information could make a great decision. When farmers got information, they could know how to deal with the outbreak. Besides, farmers also knew the good way to protect their farm which was an increase of biosecurity. This condition was in line with the study of Hidano et al., (2019). In contrast to that, a small number of pig farmers could not give a precise answer to these questions. This condition may be due to a lack of accessing information sources and communication channels and other reasons such as the availability of the Internet, mobile phone, and education (Aldosari et al., 2019).

\section{CONCLUSION}

There were four information sources including government-extension worker, farmer-to-farmer, private extension worker, feed seller, and three communication channels including farming visit, electronic media, and printed media were found out. Gender, pig herd size, 
as well as formal and informal educations affected the choice of farmers in getting information about ASF from government-extension workers while only gender and formal education affected the choice of communication channel. Furthermore, through information sources and communication channels, pig farmers can know how to prevent from ASF and deal with the ASF outbreak.

\section{CONFLICT OF INTEREST}

We certify that there is no conflict of interest with any financial, personal, or other relationships with other people or organization related to the material discussed in the manuscript.

\section{ACKNOWLEDGEMENT}

We acknowledge financial support from Research Directorate of Universitas Gadjah Mada, Yogyakarta, Indonesia with Rekognisi Tugas Akhir (RTA) grant.

\section{REFERENCES}

Akinbile, L.A. \& O.O. Otitolaye. 2008. Assessment of extension agents' knowledge in the use of communication channels for agricultural information dissemination in Ogun State, Nigeria. J. Agric. Food Info. 9: 341-353. https://doi. org/10.1080/10496500802451426

Aldosari, F., M.S. Al-Shunaifi, M.A. Ullah, M. Muddassir \& M.A. Noor. 2019. Farmers' perceptions regarding the use of Information \& Communication Technology (ICT) in Khyber Pakhtunkhwa, Northern Pakistan. J. Saudi Society Agric. Sci. 18: 211-217. https://doi.org/10.1016/j. jssas.2017.05.004

Angello, C. 2015. Exploring the use of ICTs in learning and disseminating livestock husbandry knowledge to urban and peri-urban communities in Tanzania. Int. J. Edu. Develop. Infor. Communication Tech. 11: 5-22.

Brhane, G., Y. Mammo, \& G. Negusse. 2017. Sources of information and information seeking behavior of smallholder farmers of Tanqa Abergelle Wereda, central zone of Tigray, Ethiopia. J. Agri. Extension Rural Develop. 9: 47-52. https:// doi.org/10.5897/JAERD2016.0850

FAO. 2020. ASF (African swine fever) situation in Asia. http:// www.fao.org/ag/againfo/programmes/en/empres/ASF/ situation_update.html. [6 June 2020]

Frossling, J. \& M. Noremark. 2016. Differing perceptions Swedish farmers' views of infectious disease control. Vet. Med. Sci. 2: 54-68. https://doi.org/10.1002/vms3.20

Gail, M.S. \& R.A. Anthony. 2013. Analyzing and interpreting data from Likert-Type scales. J. Graduate Med. Education. 5: 541-542. https://doi.org/10.4300/JGME-5-4-18

Guinat, C., B, Wall, L. Dixon, \& D. U. Pfeiffer. 2016. English pig farmers' knowledge and behaviour towards African swine fever suspicion and reporting. PLOS ONE. 11: e0161431. https://doi.org/10.1371/journal.pone.0161431

Guntoro, B., Subejo, \& H. Sazali. 2016. Information access capability of goat farmers in Purworejo Indonesia. Information. 19: 1819-1826.
GSO. 2019. General Statistics Organization: Population and Housing Censuses. Statistics Publishing, Ha Noi.

Kante, M., R. Oboko, \& C. Chepken. 2017. Influence of perception and quality of ICT-based agricultural input information on use of ICTs by farmers in developing countries: Case of Sikasso in Mali. Electronic J. Info. Systems Dev. Countries. 83: 1-21. https://doi.org/10.1002/j.1681-4835.2017.tb00617.x

Kipkurgat, T. 2015. Agricultural extension services for dairy farmers in Wareng district, Kenya. Int. J. Adv. Res. 3: 273-282.

Lind, D.A., W.G. Marchal, \& S.A. Wathen. 2018. Statistical Techniques in Business \& Economics. $7^{\text {th }}$ ed. McGraw-Hill Education, New York

Lindström, T., S.S. Lewerin, \& U. Wennergren. 2012. Influence on disease spread dynamics of herd characteristics in a structured livestock industry. J. R. Soc. Interface. 9: 12871294. https://doi.org/10.1098/rsif.2011.0625

Mapiye, O., G. Makombe, C. Mapiye, \& K. Dzama. 2019. Management information sources and communication strategies for commercially oriented smallholder beef cattle producers in Limpopo province, South Africa. Outlook Agric. 49: 50-56. https://doi.org/10.1177/0030727019860273

Mbanda-Obura, S.A., M. Isaiah, Tabu, M.A. David, \& R.K. Obura. 2017. Determinants of choice of agricultural information sources and pathways among sorghum farmers in Ndhiwa Sub-county, Western Kenya. Int. J. Agric. Ext. 5: 39-49.

Melesse, B., Y. Sewnet, B. Derso, \& T. Petros. 2018. Analysis of indigenous communication channels for disseminating agricultural information: The case of North Gondar zone. International Journal of Scientific Research and Management. 6: 167-177. https://doi.org/10.18535/ijsrm/ v6i7.ah01

Mittal, S. \& M. Mehar. 2015. Socio-economic factors affecting adoption of modern information and communication technology by farmers in India: Analysis using Multivariate Probit Model. J. Agric. Education Ext. 22: 199-212. https:// doi.org/10.1080/1389224X.2014.997255

Motiang, D.M. \& E.C. Webb. 2015. Sources of information for small-holder cattle farmers in Dr Ruth Segomotsi Mompati District Municipality in the North West Province, South Africa. Appl. Anim. Husb. Rural Dev. 8: 26-33.

Msoffe, G.E.P. \& P. Ngulube. 2016. Agricultural information dissemination in rural areas of developing countries: A proposed model for Tanzania. Afri. J. Library Arch. Info. Sci. 26: 169-187.

Mtega, W.P., N. Ngoepe, \& L. Dube. 2016. Factors influencing access to agricultural knowledge: the case of smallholder rice farmers in the Kilombero district of Tanzania. S. Afri. J. Info. Manage. 18: 679. https://doi.org/10.4102/sajim. v18i1.679

Nazari M.R. \& M.S.B.H. Hassan. 2011. The role of television in the enhancement of farmers' agricultural knowledge. Afri. J. Agric. Res. 6: 931-936. https://doi.org/10.5897/ AJAR10.1154

Sebeho, M.A. \& J.B. Stevens. 2019. An overview of perceptions and attitudes towards extension service delivery in Fezile Dabi District, Free State Province. S. Afr. J. Agric. Ext. 47: 61-72. https://doi.org/10.17159/2413-3221/2019/v47n1a485

Tabachnick, B.G. \& L.S. Fidell. 1996. Using Multivariate Statistics. $3^{\text {rd }}$ ed. Harper Collins, New York. 